\title{
An efficient synthesis of novel 6,12-dihydro (1)benzopyrano[3,4-b][1,4]benzothiazin-6-one
}

\author{
VandanaGupta and Archana Gupta \\ Department of Chemistry, \\ University of Rajasthan, Jaipur, India \\ E-mail: gupta_archana18@yahoo.com
}

\begin{abstract}
The condensation and oxidative cyclization of substituted 2-amino benzenethiols (I; 3,6-dimethyl- / 3,6-dichloro13,5-dichloro-/3,4-dichloro-) and 4-hydroxycoumarin (1I) in DMSO at 140-145 C yields 6,12-dihydro (1)benzopyrano[3,4b][1,4]benzothiazin-6-one. The reaction is believed to proceed through the formation of an intermediate enaminoketone (III). Under experimental conditions 2-aminobenzenthiols (I) are readily oxidized to bis(2-aminophenyl)disulfides(Ia) which cyclizes to 6,12-dihydro (1)benzopyrano[3,4-b][1,4]benzothiazin-6-one (IVa-d) by scission of sulfur-sulfur bond due to high reactivity of alpha position of enaminoketone system (III) towards nucleophilic attack.
\end{abstract}

Keywords: 2-Aminobenzenethiol, 4-Hydroxycomarin, 6,12-dihydro(1)benzopyrano [3,4-b] [1,4]- benzothiazin-6-one

\section{Introduction:}

During last thirty years, a great number of heterocyclic coumarins or quinolones have been synthesized and their biological activities extensively evaluated. Indeeed, heterocyclic coumarins and quinolones display some interesting pharmacological activities, particularly as anticoagulants, photosensibilizing drugs, estrogen mimics or antiproliferative compounds (1-8). 6,12dihydro (1)benzopyrano[3,4-b][1,4]benzothiazin -6-one constitute an important class of 1,4-benzothiazine derivatives and it has been considered worthwhile to synthesize them to explore their medicinal potential (9-10).

A series of substituted 6,12-dihydro (1)benzopyrano[3,4-b][1,4]benzothiazin-6-one have been synthesized (Scheme-I) by the condensation and oxidative cyclization of substituted 2-amino benzenethiols (I; 3,6-dimethyl- / 3,6-dichloro-/3,5-dichloro13,4-dichloro-) and 4-hydroxycoumarin (II) in DMSO at 140-145 C. The reaction is believed to proceed through the formation of an intermediate enaminoketone(III). Under experimental conditions 2-aminobenzenthiols (I) are readily oxidized to bis(2aminophenyl)disulfides(Ia) which cyclizes to 6,12-dihydro (1)benzopyrano[3,4-b][1,4]benzothiazin-6-one (IV) by scission of sulfur-sulfur bond due to high reactivity of alpha -position of enaminoketone system (III) towards nucleophilic attack.

\section{Experimental:}

Melting points were determined in open capillary tubes and are uncorrected. The purity of the synthesized compounds was checked by thin layer chromatography. The structures of all compounds were assigned on the basis of IR and NMR. IR spectra were recorded on Perkin-Elmer spectrometer in $\mathrm{KBr}$ disc. 'H NMR spectra were recorded on $300 \mathrm{MHz}$ instrument with DMSO- $\mathrm{d}_{6}$ as solvent using TMS as internal standard. 


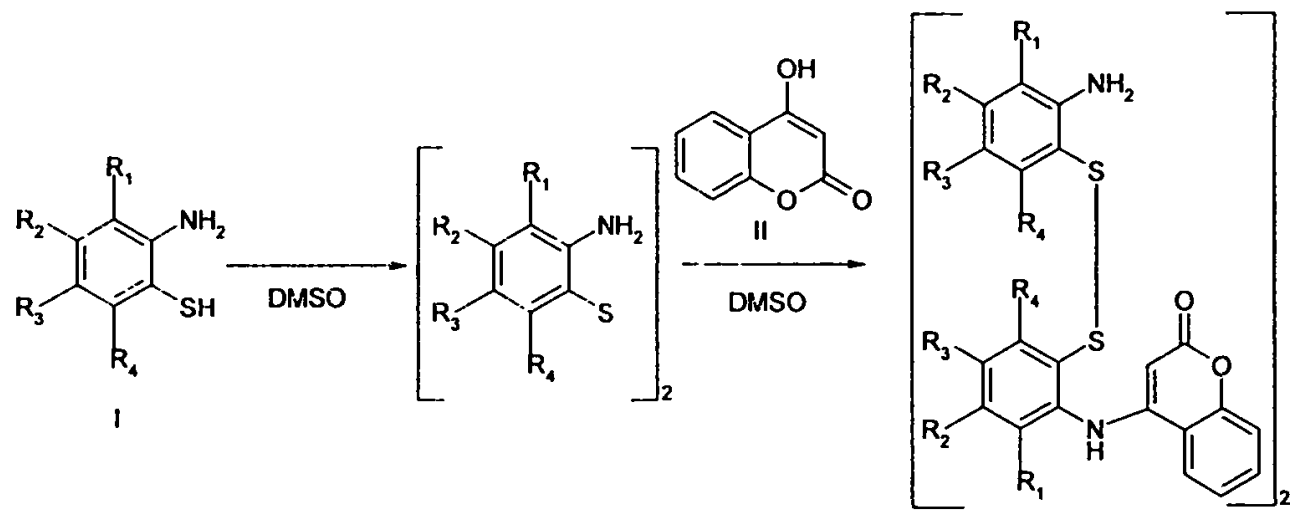

$$
\begin{aligned}
& \text { a. } R_{1}=R_{4}=C H_{3} ; R_{2}=R_{3}=H \\
& \text { b. } R_{1}=R_{4}=\mathrm{Cl} ; R_{2}=R_{3}=H \\
& \text { c. } R_{1}=R_{1}=\mathrm{Cl}, R_{2}=R_{3}=H \\
& \text { d. } R_{1}=R_{3}=\mathrm{Cl} ; R_{2}=R_{4}=H
\end{aligned}
$$

Scheme-I

\section{General Procedure fo: the Freparation 6,12-dihyd ro(1)benzopyrano[3,4-b][1,4]-benzothiazin-6-one(IVa-d)}

To a stirred solution of 4-hydroxycoumarin (II) in dimethylsulfoxide, 2-aminobenzethiol (I) was added and heated at at 140$145^{\circ} \mathrm{C}$ for $30-50$ minutes (Scheme-I). Completion of the reaction was checked by TLC. After completion of the reaction the beaker was allowed to cool to r. t. Product was collected by filtration, washed with methanol and.crystallized from methanol. This experimental procedure was followed to prepare the compounds IVa-d. The characterization data of compounds IVa-d is summarized below.

IV a IR (KBr) 3350, 1675, 1595, 1440, 1370, $\mathrm{Cm}^{-1}$; 'H NMR (90MHz, DMSO) $\delta, 8.40 .(\mathrm{s}, 1 \mathrm{H}), 6.30-7.92(\mathrm{~m}, 6 \mathrm{H}), 2.04(\mathrm{~s}, 3 \mathrm{H})$ due to $\mathrm{CH}_{3}$ Protons at $\mathrm{C}_{1}, 1.93(1 \mathrm{H})$ due to $\mathrm{CH}_{3}$ Protons at $\mathrm{C}_{4}$; Anal. calc. for $\mathrm{C}_{17} \mathrm{H}_{13} \mathrm{NO}_{2} \mathrm{~S}: \mathrm{C}-69.15, \mathrm{H}-4.40, \mathrm{~N}-4.74$ Found: C-69.30, H-4.41, N-4.76.

IV b IR (KBr) 3440, 1680, 1660, $750 \mathrm{Cm}^{-1}$; ${ }^{\mathrm{H}} \mathrm{H}$ NMR (90MHz, DMSO) $\delta, 8.43(\mathrm{~s}, 1 \mathrm{H}), 6.43-8.24(\mathrm{~m}, 6 \mathrm{H})$; Anal. calc. for $\mathrm{C}_{15} \mathrm{H}_{7} \mathrm{Cl}_{2} \mathrm{NO}_{2}$ S: C-53.28, H-2.07, N-4.17 Found: C-53.57, H-2,08, N-4.16.

IV c $\operatorname{IR}(\mathrm{KBr}) 3380,1680,1610,750 \mathrm{Cm}^{-1}$; ' $\mathrm{H}$ NMR $(90 \mathrm{MHz}, \mathrm{DMSO}) \delta, 9.66(\mathrm{~s}, 1 \mathrm{H}), 6.59-8.49(\mathrm{~m}, 6 \mathrm{H})$;

Anal. calc. for $\mathrm{C}_{15} \mathrm{H}_{7} \mathrm{Cl}_{2} \mathrm{NO}_{2} \mathrm{~S}$ : C-53.28, $\mathrm{H}-2.08, \mathrm{~N}-4.15$ Found: C-53.57, H-2,08, N-4.16.

IVd IR (KBr) 3360, 1715, 1595, 750, $\mathrm{Cm}^{-1}$; ' 'H NMR (90MHz, DMSO) $\delta, 8.40(\mathrm{~s}, 1 \mathrm{H}), 6.88-8.21(\mathrm{~m}, 6 \mathrm{H})$; Anal. calc. for $\mathrm{C}_{15}$ $\mathrm{H}_{7} \mathrm{Cl}_{2} \mathrm{NO}_{2} \mathrm{~S}: \mathrm{C}-53.69, \mathrm{H}-2.09, \mathrm{~N}-4.14$ Found: C-53.69, H-2.08, N-4.16. 


\section{References}

1. Micheli, R. A., Booth A. N., Livigston A. L., Bickoff E. M., J. of Med. and Pharmaceutical Chem. 51, 1962, 321.

2. Jacquot Y., Bermont L., Giorgi H., Refouvelet B., Adessi G. L., Daubrosse E., Xicluna A., Eur. J. Med. Chem. 36, $2001,127$.

3. Cao S. G., Wu X.H., Sim K. Y., Tan B.H.K., Vittal J.J., Pereira S.H. Goh, Helv. Chim Acta 81, 1998, 1404.

4. Fujioka T., Furuni K., Fuji H., Okabe H., Mihashi K., Nakano Y., Matsunaga H., katano M., Mori M., Chemical and Pharmaceutical Bulletin 47, 1999, 96.

5. Woo L. W. L., Purohit A., Malini B., Reed M, J., Potter B. V. L., Chem. Binl. $7,2000,773$

6. Purohit A., Woo L. W. L., Barrox D., Hejaz H. A. M., Nicholson R. I., Potter B.V.L., Reed M, J., Molecular and Cellular Endocrinology 171, 2001, 129.

7. Jacquot Y., Bermont L., Giorgi H., Refouvelet B., Adessi G. L., Daubrosse E., Xicluna A., Eur. J. Med.Chem.,36, $2001,127$.

8. Refouvelet B., Guyon C., Jacquot Y., Girard C., Fein H., Bevalot F., Robert J. F., Heyd B., Mantion G., Richert L., Xicluna A., Eur., J. of Medicinal chemistry 39, 2004, 931

9. Shah, Anamik; Naliapara, Yogesh; Sureja, Dinesh; Motohashi, Noboru; Kurihara, Teruo; Kawase, Masami; Satoh, Kazue; Sakagami, Hiroshi; Molnar, Joseph.

Anticancer Research 18,1998,61.

10. Shah, Anamik; Naliapara, Yogesh; Sureja, Dinesh; Motohashi, Noboru; Kawase, Masami; Miskolci, Csilla; Szabo, Diana; Molnar. Joseph. Anticancer Research 18, 1998, 3001.

Received on March 12, 2009 
